\section{UN ALGORITHME POUR LA RÉSOLUTION DES ANALOGIES ENTRE MOTS \\ Yves LEPAGE}

\section{Résumé}

Un rappel de travaux précédents sur l'analogie en psychologie, en intelligence artificielle et en traitement automatique des langues précède la présentation d'un algorithme de résolution, au niveau morphologique, d'analogies entre mots. Cet algorithme crée un quatrième mot à partir de trois mots donnés, quand c'est possible. Par exemple, étant donnés fable, fabuleux et miracle, l'algorithme crée bien miraculeux. Des cas bien plus difficiles sont correctement résolus par l'algorithme, en particulier, les cas d'infixation multiple, nécessaires pour rendre compte de la morphologie des langues sémitiques. Nous donnons les caractéristiques de l'algorithme et mentionnons quelques applications possibles.

\section{EIN ALGORITHMUS ZUR LÖSUNG VON WORT-ANALOGIEN Yves LEPAGE}

\section{Zusammenfassung}

Nach einer Beschreibung früherer Werke über Analogie im Rahmen von Psychologie, künstlicher Intelligenz und maschineller Sprachverarbeitung, wird ein Algorithmus zur Lösung von Wort-Analogien auf morphologischer Ebene vorgeschlagen. Dieser Algorithmus erzeugt, wenn möglich, ein viertes Wort aus drei gegebenen Wörtern. Zum Beispiel, aussähest wird aus nehmen, ausnähmest und sehen abgeleitet. Auch komplexere Fälle werden korrekt behandelt, selbst in der Morphologie semitischer Sprachen, in denen parallele Infixung vorkommt. Der Algorithmus wird beschrieben und mögliche Anwendungen werden aufgezeigt.

\section{ALGORYTM DO ROZSTRZYGANIA ANALOGII POMIẸDZY SEOWAMI}

\author{
Yves LEPAGE
}

\section{Streszczenie}

Po opisaniu poprzednich prac nad zagadnieniem analogii $w$ ramach psychologii, sztucznej inteligencji oraz lingwistyki komputerowej, pokazujemy algorytm do rozwiązania analogii pomiędzy słowami na poziomie morfologicznym. Algorytm ten tworzy, kiedy jest to możliwe, czwarty termin na podstawie trzech innych terminów. Na przykład, jeżeli podamy śpiewać, spiewaczka i dziatać, algorytm słusznie stworzy dzialaczka. Algorytm ten rozwiąuje bardziej skomplikowane problemy analogii, jak w przypadku morfologii języków semitycznych, gdzie w środku słów może pojawić się kilka przyrostków jednocześnie. Opisujemy algorytm i jego możliwe zastosowania.

\section{単語の類推関係解決手法}

Yves LEPAGE (ルパージュ) 